\title{
NOS PASSOS DOS CLÁSSICOS: ECOS DO BUCOLISMO ANTIGO NA PRIMEIRA LIRA DE MARÍLIA DE DIRCEU*
}

\author{
Matheus Trevizam**
}

\begin{abstract}
Resumo: Propõe-se, neste trabalho, mostrar alguns traços da lira primeira de Marilia de Dirceu, do árcade português Tomás Antonio Gonzaga, cuja existência nos remete, em geral, à tradição da poesia pastoril e, especificamente, à segunda Bucólica de Virgilio. São elementos de ordem temática, estrutural, retórica e genérica, aos quais poder-se-ia atribuir a tentativa de diálogo do autor setecentista com o passado da literatura clássica. Assim, através do destaque do que Gonzaga deve a tais predecessores, fazse também ver sua contribuição particular ao bucolismo.
\end{abstract}

\section{INTRODUÇÃO}

A expressão poética em nossa língua, ainda em fins do Século das Luzes, foi tributária de meios artísticos solidamente enraizados na tradição antiga. Referimo-nos, especificamente, ao corpus então composto pelos representantes do arcadismo no Brasil e em Portugal: muito embora, esclarecem-nos com freqüência as histórias literárias, tal moda deva seu ressurgimento a uma certa influência italiana ${ }^{1}$, não há por

\footnotetext{
* Recebido para publicação em julho de 2007.

* Professor da Faculdade de Letras/UFMG.

1 Candido (1993, p. 57-58): Escolhendo a designação de Arcádia Lusitana para o seu grêmio, os reformadores da literatura portuguesa se conformavam ao exemplo italiano; ao cultivarem o gênero bucólico, ou adotarem nomenclatura bucólica nos seus poemas, integravam-se numa corrente, também de inspiração italiana imediata, mas de boas, excelentes raízes portuguesas; corrente que parecia a própria condição de um movimento cujo escopo era restabelecer a simplicidade e desbaratar a joalheria falsa do Cultismo decadente.
} 
quê, uma vez rediviva a tradição, seus novos praticantes não possam ser considerados atualizadores de pressupostos a remeter-nos diretamente a letras mais longínquas.

Isso se dá, esclarecemos, sem que se faça preciso "provar" a presença de um poema antigo qualquer como única e inequívoca fonte imitativa eventual dos árcades de língua portuguesa, mas de maneira genérica, no sentido do termo nos estudos literários, ou retórica. Com efeito, segundo os preceitos de várias artes poéticas, sabemos que os antigos e seus seguidores previam a feitura de obras em conformidade com regras destinadas a definir tipos compositivos excludentes entre si ("gêneros") 2 e, até certo ponto, "fechados" dentro de limites dados.

Assim, para um tipo genérico como a poesia épica ou, o que nos interessa presentemente, bucólica, estabelecia-se, apesar das coincidências vinculadas, por exemplo, ao metro (com o emprego do hexâmetro datílico por Virgílio tanto na Eneida quanto nas Bucólicas), que as diferenciava a escala representativa das personagens e da "ambiência" social, bem como a extensão e o "tom" do canto e as situações enunciativas postas em funcionamento com o fazer dos textos. ${ }^{3}$

2 Na Arte poética de Aristóteles, por exemplo, introduz-se a partir da primeira parte a diferenciação dos gêneros da epopéia, da comédia, da tragédia e do ditirambo com base nos "meios", "objetos" e "maneiras" imitativas utilizados (ARISTÓTELES, 1981, p. 19).

3 A epopéia, com efeito, focaliza, segundo Horácio (HORÁCIO, 1981, p. 57), "os feitos de reis e capitães nas guerras funestas" - entre v. 70-80; além disso, os poemas a realizarem-na eram longos a ponto de serem divididos em cantos, situavam-se no topo da escala representativa antiga e centravam-se na "voz" de um narrador épico externo aos eventos, com eventual "intromissão" de personagens-narradores (como Ulisses, Enéias, etc...); a poesia bucólica, por sua vez, tratava de um mundo fictício rural onde interagiam pastores, produziu "espécimes" de extensão confinada a algumas dezenas de versos (com 73 na segunda Bucólica), foi classificada entre os gêneros de mais baixa escala pelos autores antigos e recorria, sobretudo, ao monólogo ou diálogo entre personagens (FEDELI, 1991, p. 77-84). 
Justifica-se dessa maneira o ocasional "parentesco" entre os textos arcádicos de nossa Ilustração periférica e outros compostos ainda no século I a.C. pelo jovem Virgílio. Especificamente, propomos aproximar como "modelo" da lira inicial de Marília de Dirceu, de Tomás Antônio Gonzaga, a segunda Bucólica daquele autor antigo. De uma forma no mínimo autorizada pela "coincidência" do gênero, ou pelo irrefutável predomínio clássico sobre as letras ocidentais do Renascimento até a aurora romântica (CANDIDO, 1993, p. 41), vemo-nos em ambos os casos diante de produtos artísticos afins, cuja ressonância significativa recíproca se faz pertinente pelo fato mesmo de os referenciais antigos decerto corresponderem, no contexto primeiro de escrita e leitura da obra vernácula em questão, a dados de cultura funcionalmente vivos.

$\mathrm{Na}$ análise iniciada adiante intentaremos, pois, "encaixando" Gonzaga sobre os "rastros"; de Virgílio, determinar-lhe os pontos de direta intersecção com esse veio criativo peculiar da literatura européia, e ainda apontar para o que seriam indícios de uma direta imitação do romano por nosso árcade no poema mencionado.

\section{LEITURA COMPARATIVA DOS POEMAS}

Já pelas situações enunciativas gerais, o texto latino e o árcade assemelham-se: trata-se, com exceção do início e do fim da segunda Bucólica, de conceder a "voz" a um pastor apaixonado a fim de que busque comover por suas palavras. No poema antigo, assim, Córidon, figura de poeta rústico desprezado pelo belo Aléxis, extravasa só e pateticamente seu desespero em meio a uma natureza identificável com as típicas paragens do gênero (onde é grato aos rebanhos refrescar-se 
na sombra e crescem faias sobre os montes). Por sua vez, o "eu" da lira em pauta furta-se, como convinha ao decoro dos setecentos, ao homoerotismo antigo para dirigir-se a Marília como dúbia interlocutora de um convite amoroso: ao contrário da obviedade do poema virgiliano neste ponto, talvez não nos encontremos aqui diante de um "monólogo ao deserto", o que inviabilizaria assegurar a distância física entre a interlocutora e Dirceu.

Em que pese a esse pormenor, no entanto, seria possível apontar a existência de muitos dos pressupostos da poesia bucólica em sua trama comum:

"Representante da estética alexandrina, Teócrito fora buscar seus temas nas classes laboriosas do campo e da cidade e, a partir de argumentos extraídos da vida quotidiana, compusera poemas breves de uma estética cuidada, nos quais criava um novo espaço poético. [...] É a Teócrito, todavia, que Virgílio se refere para definir o gênero pelo qual começa sua carreira poética. É um gênero pequeno, ligado ao campo, como diz desde a primeira écloga (verso 2): "tu te aplicas à musa silvestre com a tênue avena", o que repete na écloga VI (verso 8): "aplicar-meei à musa agreste com o tênue cálamo". [...] $\mathrm{O}$ cálamo é, pois, o emblema da poesia bucólica, que é inseparável da música". ${ }^{4}$

4 Cf. prefácio de J.-P. Néraudau à tradução francesa das Bucólicas virgilianas (VIRGÍLIO, 2002, p. XI), aqui em minha tradução portuguesa. 
Ora, o gênero bucólico, de fato ligado desde seu criador aos pequenos eventos do quotidiano de pastores poeticamente urdidos, pressupunha uma espécie de enfoque muito preciso sobre a vida humana: tendo como invariáveis protagonistas seres recobertos pelo "disfarce" rústico, ${ }^{5}$ franqueava-nos um mundo idílico e pouco documental, no sentido de não se pretender um registro exato dos fazeres na Sicília dos tempos de Teócrito, na Itália de Virgílio e na região mineradora brasileira dos setecentos.

Por outro lado, conserva-se ainda a verossimilhança pela abordagem, como se disse, de quadros alúsivos a práticas ao menos passíveis de ocorrerem entre camponeses "isolados" da civilização: trata-se de representar os esforços de guarda dos rebanhos, as casuais disputas entre os homens pela primazia amorosa ou em matéria poética, suas tristezas e alegrias simples diante das mudanças da sorte, eventualmente, no caso de Gonzaga e Virgílio, de prefigurar uma convivência "familiar" alheia a grandes ambições, em todo seu potencial gerador de felicidade...

Dentre esses elementos em geral arrolados como partes da vida bucólica no gênero correspondente, todos se encontram representados em pelo menos um dos poerras de que nos ocupamos aqui: além da supracitada menção ao desejo de coabitar em sossego com o objeto dos amores, tem-se que tanto Córidon (v. 19-20) quanto Dirceu (v. 7-8 da primeira estrofe) aludem a seu estado de prósperos criadores, o primeiro tenta sem sucesso ganhar Aléxis do senhor (v. 2), regozijam-

5 Referimo-nos, aqui, ao mecanismo da "delegação poética", relativo ao fato, no bucolismo, de se porem como porta-vozes de cantos eruditos homens rústicos por definição. De uma maneira ou de outra, assim, esse descompasso entre meios expressivos e emissores acabava por "denunciar" a condição dos pastores bucólicos como construtos ou "máscaras" enunciativas dos verdadeiros poetas. 
se ambos com a mera presença dos amados (Virgílio, v. 45/ Gonzaga, v. 7-8 da quarta estrofe) e sofre-se com a repulsa (Virgílio, v. 6).

Quanto ao "cenário" de desenvolvimento do "drama" bucólico nos autores, ocorre, como se tem amiúde notado no caso da produção do árcade luso, que a natureza americana se apaga da lira primeira, ${ }^{6}$ sendo sistematicamente substituída por elementos típicos da flora e, em menor escala, do clima e da topografia mediterrâneas. Assim, medram oliveiras (v. 6 da estrofe primeira), prados (v. 6 da estrofe terceira) e ciprestes (v. 5 da estrofe sétima) pelos montes (v. 6 da estrofe terceira) e campinas (v. 6 da estrofe sexta) onde pastam os rebanhos de Dirceu (v. 6 da estrofe sexta); torna-se preciso, com o sol a pino, fazer a sesta (v. 3 da estrofe sexta). E Córidon, segundo dissemos, pondo-se em meio a um ermo absoluto descrito por Virgílio como o topo de um monte densamente copado (v. 3-5), menciona, muito além das ovelhas, lagartos (v.9), espinheiros (v. 9), arvoredos (v. 13), cigarras (v.13), alfeneiros (v. 18), lírios "negros" (v. 18), águas (v. 26), cervos (v. 29), louros (v. 54) e mirtos (v. 54).

Socialmente, ou nos termos da experiência humana em foco, roça-se com freqüência pelo mais corriqueiro: no esteio das observações de Antônio Candido sobre outra lira do mesmo árcade, um contraponto setecentista do Epicurismo virgiliano, a que se poderia atribuir o ideal da aurea mediocritas almejado na segunda Bucólica, é a vida burguesamente afim ao desejo de uma pacata segurança (CANDIDO, 2002, p. 24). Isso explica a satisfação do "pastor" apresentado, embora sem espaço para luxos, como dono de terras generosas a darem-lhe "vinho,

Candido (1993, p. 68): Silva Alvarenga, que canta a onça, o gaturamo, a cobra, a mangueira, o cajueiro, não é esteticamente menos neoclássico do que Tomás Gonzaga, que os ignora. 
legume, fruta, azeite" (v. 6 da estrofe primeira), "leite" (v. 7) $\mathrm{e}$ "finas lãs" (v. 8). No autor antigo, a face banal da felicidade pretendida faz-se sentir sobretudo nos versos 28-53, em que o cantor exprime desejos relativos a uma impossível vida futura ao lado de Aléxis. Caso ele não se encontrasse preso aos laços amorosos do dono, poderia, então, dividir uma choupana e campos humildes com Córidon (v. 28-29), dedicar-se à caça, a tocar os bodes para as plantas (v. 30), a cantar em imitação de Pã com a flauta de cana (v. 31-34), receber presentes de flores (violetas, papoulas, narcisos... - v. 45-50) e frutos (castanhas, ameixas... - v. 51-53) das ninfas e do amante...

Antes de passarmos ao breve tratamento da questão do registro lingüístico "despojado" como marca comum da escrita desses poetas vinculados ao gênero bucólico, fazemos atentar para um pormenor do quotidiano em que se aliam não só as práticas imaginárias dos pastores, mas também implicações de caráter auto-reflexivo. Pois, com mencionarem Virgilio a flauta de canas (v. 31-39) e Gonzaga sua moderna "sanfoninha" (v. 5 da estrofe segunda), aludem simultaneamente a um dado concreto da vida humilde (podendo-se crer que, na solidão dos montes, a música rústica tenha sido amiúde companheira de pastores) eà feitura de obras em "tom" menor. Havendo, então, no gênero bucólico, identidade entre os emissores fictícios do canto e figuras de homens banalizados pelo mundo pastoril, é óbvio que os dizeres produzidos por seu "intermédio" deveriam ajustar-se, por força do decoro poético, à escala de tais personagens, sem quaisquer chances, por exemplo, de ouvirmos os "toques" de tubas marciais. ${ }^{7}$

7 Já nos versos iniciais da Arte poética (HORÁCIO, 1981, p. 55), Horácio avisara contra os riscos da falta de harmonia em quaisquer composiçōes artísticas. 
Quanto à "simplicidade" do registro expressivo dos bucólicos considerados, finalmente, basta-nos remeter o leitor a certas colocações abalizadas dos críticos. Antônio Candido, assim, num despretensioso ensaio analítico já citado (2002, p. 22), ressaltou uma estranha "limpidez", em se tratando de uma obra artística composta ainda no século dos últimos arpejos barrocos, da linguagem utilizada na lira quinze da segunda parte de Marilia de Dirceu ("eu, Marília, não fui nenhum vaqueiro,/ fui honrado pastor da tua aldeia"). É que, como esclarecera em outra parte, importava ao neoclassicismo estabelecer relações de uma serena "equivalência" entre a linguagem e o mundo, sem conceder à primeira, como pouco antes se fizera, a licença de "sobrepujar" impetuosamente os referentes (CANDIDO, 1993,p. 53). Isso não significava, porém, que naquela lira, bem como na de que nos ocupamos aqui, houvesse lugar para a expressão de "vozes" genuinamente populares: a serena e contida correção lingüística dos versos portugueses pressupõe nos dois casos um emissor factual bem. afinado com a moda literária do tempo, algo impossível para um mero campesino...

Posicionando-se sobre a língua das Bucólicas virgilianas, Fedeli, por seu turno, criticou a posição de muitos estudiosos inclinados e ver nela a inequívoca expressão do pitoresco e popular, como seo autor, "de acordo" como célebrejulgamento de Sérvio sobre o estilo humilis da obra, de fato tivesse baixado a um nível corriqueiro de expressão por imitar com fidelidade. Em vez disso, propõe que se pense na tal "simplicidade", apontada como traço distintivo da dicção do poeta nesta obra desde tempos longínquos, com os sentidos descritos abaixo: 
"Com isso, não se pretende afirmar que os bucólicos sejam um exemplo de estilo elevado: sua língua não é a solene do epos, nem se põe em pé de igualdade com o modo da Eneida. Ao lado dos tons enfáticos, coexistem acentos de um tipo muito distinto: é preciso, seja como for, evitar distinguir vulgarismos em toda parte $\mathrm{e}$ ver neles uma intenção particular da parte de Virgílio; o nível humilis do estilo de Virgílio não significa aderência ao sermo communis. Trata-se de um estilo que se diferencia intencionalmente da língua falada para conformar-se a tons mais elevados, por vezes áulicos". 8

Retoricamente, intentamos que se considerem ambos os poemas exemplos complexos do gênero deliberativo: afinal, havendo neles a fala voltada para os objetos do amor, deseja-se, no final das contas, conciliar-lhes as graças e obter as alegrias futuras da aquiescência e do convívio. Como se nota, essa descrição sumária dos movimentos discursivos gerais dos dois poemas permitir-nos-ia classificá-los assim pelo fato bem estabelecido, desde as lições de Aristóteles, dos evidentes nexos entre o modo de persuasão citado e quaisquer "convites" com vistas ao útil por uma ou outra forma de agir." Em outras palavras, parece-nos que os pastores em pauta coligem argumentos decisivamente atuantes no sentido de,

8 Fedeli (1991, p. 83): [aqui, em minha tradução portuguesa].

9 Arisłóteles (2002, p. 14): Y el fin para cada uno de éstos es diferente, y son tres para los tres que son: para el que delibera, lo conveniente y lo dañoso, pues el uno, exhortando, delibera de la mejor manera; el otro, disuadiendo, disuade de lo peor; y añade las otras cosas a ésta, o justo, o injusto, o hermoso o vergonzoso - 1358b 20 . 
obtendo-se o desvio de Aléxis e Marília da via do desprezo, mostrar-lhes as vantagens da vida comum.

Ocorre, porém, que também se fazem elogios não só às pessoas dos pastores a almejarem o bem da satisfação amorosa, mais ainda aos alvos do afeto: em Gonzaga, então, ao lado da sutil referência à suavidade dos traços do "eu-lírico" (v. 3-4 da estrofe primeira, v. 1-2 da estrofe segunda), à sua mediana prosperidade (v. 5-8 da estrofe primeira), ao respeito dos demais à sua posição social (v. 3-4 da estrofe segunda) e à autonomia e sucesso de seu canto (v. 5-8 da estrofe segunda), vemo-lo enaltecer Marilia como mais merecedora de apreço do que tronos e rebanhos (v. 5-8 da estrofe terceira), anteporIhe o riso às ambições e cuidados mundanos (estrofe quinta) e, sobretudo, pronunciar-se nesses termos:

"Os teus olhos espalham luz divina, A quem a luz do Sol em vão se atreve;

Papoila ou rosa delicada e fina

Te cobre as faces, que são cor da neve.

Os teus cabelos são uns fios d'ouro;

Teu lindo corpo bálsamos vapora.

Ah! Não, não fez o céu, gentil pastora,

Para glória de Amor igual tesouro!"10

Acima, encontram-se alguns dos mais característicos topoi descritivos da beleza feminina nos séculos clássicos da literatura: olhos cujo brilho se equipara ao de sóis ou diamantes, faces de neve coloridas pelas "flores" das maçãs, fios de ouro no lugar de cabelos... ${ }^{11}$ Dir-se-ia, por sinal, que

10 Gonzaga (2001, p. 3).

1 Candido (1993, p.53): [em citação do barroco espanhol Quevedo]: "crespa tempestad del oro undoso". 
em nada transparece aqui uma Marília diferenciada dos estereótipos a caracterizarem suas "irmãs" e musas de poetas desde o Renascimento ou o Barroco "preterido", embora a restrição desses comuníssimos usos descritivos a uma única estrofe contribua para mitigar quaisquer excessos prejudiciais à placidez neoclássica do poema.

A segunda Bucólica virgiliana, por sua vez, mostra-nos um Aléxis candidus (v. 16) e formosus (v. 17), um Córidon que não receia competir em beleza com Dáfnis (v.26-27), vagamente "rico" em rebanhos e leite (v. 20), além de possuidor de mil ovelhas nos montes da Sicília (v. 21)...

Que estariam, então, esses topoi diretamente relacionáveis ao gênero demonstrativo desempenhando em peças que propusemos antes de mais nada próximas da retórica deliberativa? Sem a necessidade de sacrificar-se a unidade do movimento argumentativo dos textos, julgamos que os elogios tecidos por Dirceu para sua pastora relacionamse a uma espécie de estratégia de captatio beneuolentiae: embora não se encontrem no início do poema, segundo o usual para uma disposição mais canônica, ${ }^{12}$ cumprem bem seu papel de exprimir o embevecimento do apaixonado ao mesmo tempo em que, talvez, cativariam a mulher.

O mesmo não se dá similarmente no caso dos discretos elogios a Aléxis pela boca de Córidon, por dois importantes motivos: em primeiro lugar, trata-se, ao fazê-lo, bem mais de exprimir "realidades" quase que com automatismo do que de compor o discurso com vistas ao preciso objetivo de impressionar. Afinal, os supracitados formose (v. 17) e candidus (v. 16), ditos tão de passagem, auxiliam menos o vislumbre dos consideráveis dotes do amado do que a intensidade patética da súplica em versos anteriores (v. 6-7, por exemplo)

12 Cf. Rhetorica ad Herennium. Texte revu et trad. par Henri Bornecque. Paris: Garnier, s.d., I, VII. 
e o absurdo deslocamento solitário de Córidon pelos campos ardentes, quando toda a natureza se resguardava do meio-dia (v. 8-13).

Por outro lado, como o comprova a exata coincidência de um dos atributos apresentados como marca distintiva da beleza de Aléxis diante do "negrume" de Menalcas (v. 15-16), em qué pese às chances de justapor diretamente sua alvura e a de Marília, de que adiantaria, em termos práticos, dizê-la ao nada? O amado, bem o vimos, encontrava-se decerto longe, talvez nos braços do amo, de qualquer maneira insensível aos ardores desse que o celebrava com cantos de desvairio...

Mas, acreditamos, os elogios de cada pastor a si próprio acabam por associar-se a efeitos potencialmente afins nas obras dos poetas romano e português: como seria esperado para homens desejosos de seduzir alguém, identificam-se com a enumeração de pontos positivos em sua pessoa, de modo que alguém a escolhê-los por companheiros tivesse bons motivos para isso. Assim, mesmo diante do alheamento do puer em Virgílio e do previsível fracasso de toda a estratégia argumentativa de Córidon, trata-se de palavras carregadas de evidente força persuasiva por remeterem a traços mais do que desejáveis na figura de um parceiro amoroso (aspecto físico apetecível, "boa" posição garantida pelas posses, algum talento, aqui manifesto pela própria possibilidade de emanar o canto rústico...).

Também em Gonzaga essas qualidades soam atrativas: sendo maduro (ou "respeitado"), mas ainda de bom aspecto, pode garantir à amada ao mesmo tempo a segurança necessária a uma vida de relativo sossego material e, em se tratando ela possivelmente de uma mulher mais jovem, ${ }^{13}$ alguma vitalidade e alinho a fazer jus ao grau desses atributos nela própria.

13 Remetemos o leitor ao. real noivado de Gonzaga com a adolescente Maria Dorotéia Joaquina de Seixas, filha de familia bem situada em Vila Rica (CANDIDO, 1993, p. 112). 
Poder-se-ia dizer, pois, que tal parte do bem dizer em cada poeta vincula-se mais propriamente à tarefa do orador deliberativo do que aquela, como vimos, afim ao enaltecimento dos dotes dos amados com o objetivo de cativá-los pelo coração. Desse modo, dentre os lugares do útil, tal como presentes na Rhetorica ad Herennium ${ }^{14}$ e utilizados pelos poetas ao longo dos textos aos quais nos referimos aqui, é proveitoso lembrar, além das vantagens do estabelecimento de vínculos amorosos com pretendentes belos e prósperos, ${ }^{15}$ a presença do topos da medida (modestia), ${ }^{16}$ sobretudo na quinta estrofe de Gonzaga, ao mencionar Dirceu seu alheamento aos bens em geral cobiçados pelo vulgo estranho à peculiar "aristocracia do espírito" de que se pretende parte.

Conforme revela o prosseguimento da leitura das duas estrofes restantes dessa lira, seria possível estender a vigência de tal topos também para ambas, já que a vida simples pretendida por Dirceu ao lado de sua pastora (com passeios dos amantes na floresta - v. 1-2 da estrofe sexta - , sestas em boa companhia - v. 3-4 da mesma estrofe - jogos deleitosos de enfeite dos cabelos da amada com boninas e arranhandolhe o nome sobre as cascas das árvores - v. 7-8 da mesma estrofe - e as chances de um enterro em campa comum depois da morte - v. 1-8 da estrofe sétima) prefigura ainda um caminho existencial de todo próximo do equilíbrio.

E, dada a indelével união entre ética e caminho de vida "honesto" na concepção dos árcades de nossos setecentos,

\footnotetext{
14 Cf. Rhetorica ad Herennitum, III, II 3 ss.

15 De acordo com a descrição do lugar deliberativo da prudência (prudentia) pelo anônimo responsável pela escrita da Rhetorica ad Herennium (III, III 4), tratar-seia aqui talvez de recorrer a essa maneira de argumentar, pois, com sugerir-se implicitamente que é melhor escolher o bonito e o abundante e rejeitar o feio e o escasso, que se faz exceto recomendar cautela para com as boas escolhas?

16 Cf. Rhetorica ad Herennium, III, III 5.
} 
por que não explicitar em tudo o que se propõe à amada nos termos de uma pacata existência sentidos de afinamento com as coisas probamente feitas? Com efeito, ao bifurcar o útil imprecisamente associável ao gênero deliberativo, o tratadista da Rhetorica propusera, ao lado do lugar da segurança ( $t u t a$ res), o da honestidade (honesta res), repartindo esse último, numa dada direção, entre a prudência, a justiça, a força de espírito e a medida. ${ }^{17}$

Isso significa que, ao dissuadir da falta de cuidado com escolhas estranhas à rota da verdadeira felicidade (por exemplo, optando-se por parceiros amorosos dotados física ou materialmente aquém do preciso) e da vil cobiça, nosso "orador" contribui para a atribuição de um tom, como anunciamos, ético a seus argumentos. Mesmo em se tratando do lugar da prudência tal qual desenvolvido ali, as escolhas acertadas revestem-se de sentidos morais, pois os bens do parceiro cujo usufruto se espera assegurar à bela, sem serem de modo algum excessivos, integram um horizonte de vida em que a dignidade jamais poderia prescindir do acesso a algumas "comodidades": assim, bom é o modo de agir do pastor também por resultar nas chances de ter o que oferecer honestamente a uma amada atenta. ${ }^{18}$

O mesmo dar-se-ia quanto ao uso dos topoi no discurso de Córidon? Até certo ponto, sim: persiste aqui, por exemplo, a supracitada destinação de todos os elogios a ele próprio e a seu modo de vida a "ganhar" o amado. Por outro lado, por ter mencionado a suavidade do reflexo de seu semblante nas

17 Cf. Rhetorica ad Herennium, III, II 3.

18 Cf. prefácio de Ivan Junqueira à edição de Marilia de Dirceu preparada por Sergio Pachá (GONZAGA, 2001, p. XIII): Para Rodrigues Lapa, por exemplo, a obra de Gonzaga, "no que tem de mais profundo e certamente mais duradouro, é a viva concretização do ideal familiar e burguês para que tendiam os espíritos do século XVIII". 
águas (v. 25), bem como, a título de exemplificação, suas mil ovelhas a pastarem nos montes sicilianos (v. 21), ele também aponta para vantagens ${ }^{19}$ de sua pessoa diante de quaisquer outros pretendentes futuros ao amor de Aléxis (como Dáfnis! - v. 26).

A passagem para o devaneio da vida comum, por seu turno, também se poderia dizer "contaminada" pelo lugar da modestia, já que, muito embora Aléxis, possivelmente gaté pelo senhor e amante, desdenhe mais de uma vez os dons simples que Córidon pode oferecer-lhe (v. 43-44, v. 56-57), esse, enfim, não parece determinado a mudar de vida para agradar a ninguém... Do ponto de vista biográfico, embora não seja, em absoluto, forçoso endossar a anedota antiga sobre a ardente paixão de Virgílio por um jovem escravo de propriedade de Mecenas ou Asínio Polião como ponto de partida criativo para esta Bucólica, ${ }^{20}$ julgamos de interesse lembrar que, pouco antes do início da escrita da antologia em que se insere (anos 45-44 a.C.), o poeta consagrara-se à vida filosófica na escola napolitana de Sirão. ${ }^{21}$ Esse, cultor do Epicurismo, decerto soubera influenciar em parte a disciplina mental do autor em seus momentos iniciais de dedicação ao ofício compositivo; desse modo, como não supor que muito do entusiasmo manifesto nas Bucólicas pelas alegrias rústicas (caso não só do ideal de vida frustrado no poema visto pela inflexível recusa de um Aléxis, mas ainda do doce repouso de Títiro nos limites de suas terras, tal qual descrito na primeira écloga),

19 Cf. dito quatro notas antes sobre o lugar da "prudência" no gênero deliberativo.

${ }^{20}$ Cf. explicação de J.-P. Néraudau à segunda Bucólica virgiliana (VIRGÍLIO, 2002, p. 14).

21 Cf. introdução de J.-P. Nèraudau às Bucólicas virgilianas (VIRGÍLIO, 2002, p. IX). 
em todo seu potencial de dotar o homem do necessário para a satisfação das mais básicas necessidades, possa ter raízes nessa experiência?

Isso nos autorizaria a propor tal coloração filosófica específica para o "revestimento" do topos da modestia num momento específico das imprecações de Córidon (v. 28-55), de maneira que a obra resultasse "aclimatada" à época e às afiliações intelectuais da mocidade do poeta. Mas, de um modo completamente ausente em Gonzaga, amiúde pautado pela serenidade mesmo nas liras posteriores aos desastrosos desdobramentos pessoais de seu envolvimento no episódio da Inconfidência Mineira, Córidon recorre ao patético como forma destacada de fazer-se comovente a um amado ausente: ei-lo, assim, em v. 6-7, a interpelar interrogativamente Aléxis à cata de algum mínimo olhar para sua dor e dizendo que é obrigado a morrer; e, em v. 14-16, após o relato de seu exasperado "passeio", na verdade um vagar'sem destino em meio às condições caniculares do verão meridional, a relembrar desgastado as desilusões anteriores com Menalcas e Amarílis, momentos igualmente espinhentos para seu coração...

No todo, porém resulta do cotejo de ambos os poemas forte impressão de similaridade em aspectos relacionados não só ao uso dos topoi e à "eleição" do gênero retórico mais bem adaptado a exprimir o convite amoroso, mas, fundamentalmente, à disposição seqüencial das partes internas a cada um deles. Nesse sentido, chamamos de início a atenção para o grande corte operado em Virgílio entre v. 28ss. e a parte introdutória da segunda Bucólica, com o contraponto, em Gonzaga, do contraste entre os trechos anterior e posterior à sexta estrofe da lira primeira. Trata-se, como já assinalamos ${ }^{22}$

22 Baseando-nos, para isso, nas análises de Candido (2002, p. 25-26) a respeito da lira quinze da segunda parte de Marilia de Dircet. 
e é muito fácil perceber, de adotar a técnica do flash forward na evocação da vida futura comumente partilhada pelos amantes, havendo sempre, no instante mesmo de enunciação das súplicas, vaga ou nenhuma chance de experimentar as alegrias de conviver em paz com quem se quer.

Em outras palavras, segue-se a um presente de desejos e planos futuros a figuração prévia dos bons momentos de que poderão desfrutar juntos os amantes reunidos, apenas com haver a aquiescência final de Marilia ou Aléxis... Ora, diante dessa seqüência divisamos um padrão compositivo com grande probabilidade sugerido a Gonzaga pela obra do célebre mantuano: não sendo de maneira alguma necessário que, rogando os amores de Marilia, Dirceu se furtasse depois à realidade imediata para o esboço de seus sonhos nas brumas do devaneio, esse proceder viera-lhe das leituras de Virgílio.

Ainda sobre essa questão, parece importante apontar o "espelhamento" entre a lira inicial de toda a obra, tal qual aqui tratada, e a lira quinze da segunda parte de Marília de Dirceu: Antônio Candido (2002, p. 34), com efeito, sem referir-se ao primeiro poema, chegara a mencionar as idéias de Alberto Faria ${ }^{23}$ sobre o processo imitativo de Gonzaga ao estruturar o segundo nos passos da Bucólica em pauta nesta análise. Se de fato for assim, encontramos nos juízos desse crítico mencionado de passagem mais um ponto de apoio para propor a segunda Bucólica virgiliana como foco de origem dos principais desenvolvimentos presentes na lira primeira: esses dois poemas em português, inegavelmente, manifestam óbvios pontos de contato estruturais e tópicos, fazendo-nos crer na modelagem daquela lira posterior sobre a inicial, e não

23 Sobre a obra de Faria, por ele citado, note-se: Faria (1922). 
o avesso. Explica-se: o poema da segunda parte, seguindo-se à queda em desgraça de Gonzaga pela acusação com os demais inconfidentes do crime de lesa-majestade e possivelmente composto enquanto ele se encontrava detido na prisão carioca da Ilha das Cobras, incorpora à trama poética dados alusivos às dificuldades biográficas do autor naquele momento dado (CANDIDO, 2002, p. 33). Dessa maneira, não se encontrando em absoluto essas referências na lira inicial da obra em vista, pode-se concluir não apenas por sua anterioridade cronológica em relação ao outro poema, mas, fundamentalmente, o que nos interessa agora, por sua condição de ensaio primeiro para o desenvolvimento do exercício imitativo quanto à arte de Virgílio.

Além da divisão temporal entre a realidade do presente, neste caso apresentado como sombrio, e as brumas de um futuro agora comprometido com o ganho de algo da dignidade perdida ao lado de Marília, notem-se expressões como estas: "eu, Marília, não fui nenhum vaqueiro,/ fui honrado pastor da tua aldeia;/ vestia finas lãs e tinha sempre/ a minha choça do preciso cheia", "prezava o teu semblante, os teus cabelos/ ainda muito mais que um grande trono", "se o rio levantado me causava,/ levando a sementeira, prejuízo,/ eu alegre ficava, apenas via/ na tua breve boca um ar de riso" e "propunha-me dormir no teu regaço/ as quentes horas da comprida sesta,/ escrever teus louvores nos olmeiros,/ toucar-te de papoilas na floresta"... Ora, em todos os casos são dizeres que nos remetem diretamente à lira inicial de Marilia de Dirceu, com signos inequívocos de re-elaboração poética; em vários momentos, por sinal, retomam-se palavras e 
expressões ipsis litteris do outro contexto compositivo! ${ }^{24}$. Curiosamente, o próprio Gonzaga demonstra com o uso dos tempos verbais a trajetória de escrita do todo de Marília de Dirceu: ao dizer, apontando para um passado "biográfico" na existência de seu pastor, "prezava o teu semblante", "o rio levantado me causava", "propunha-me dormir no teu regaço". e outras expressões que tais, todas, como vimos, passíveis de remeter-nos à lira introdutória dessa antologia, que faz ele exceto pôr-se, em termos do fluxo de escrita, num momento bem subseqüente ao do urdume daqueles versos?

E, segundo uma diferença fundamental entre um e outro poema arcádico, o esperançoso Dirceu da primeira parte não tinha um passado para que olhar nostalgicamente, nem se identificava seu futuro com a esperança de re-criar os bens perdidos com o auxílio da bela, mas, quase satisfeito com seu estado de fortuna e desejoso de completar-lhe a ventura com a companhia de Marília, tão somente pensava coroar-se através da aquisição do mais precioso.

Tais fatores, parece-nos, esclarecem a natureza dos nexos entre as duas liras vistas (tomando a primeira ea segunda mencionadas, com o respectivo estado de fonte e caldatária uma em relação à outra), bem como, no tocante ao legado clássico de Virgílio, entre ambas e sua Bucólica. Num rico jogo de mecanismos imitativos e alusivos, pois, pode-se dizer que Gonzaga, como bom literato culto dos setecentos, soube servir-se da obra antiga com vistas à sucessiva elaboração de textos passíveis de exprimirem momentos peculiares de sua sensibilidade (haja vista o entremeio "dinâmico" da história de amor pessoal por Maria Dorotéia Joaquina de Seixas na trama de ambos).

24 Cf., por exemplo, no primeiro dos poemas, v. 1-2 da estrofe inicial: "Eu, Marília, não sou algum vaqueiro,/ que viva de guardar alheio gado" (GONZAGA, 2001, p. 3). 
Graças a essas felizes iniciativas, portanto, vemo-lo capaz de imprimir sua marca artística a meios expressivos tão tradicionais no ocidente e, ao mesmo tempo, entroncar com sucesso o débil ramo de nossa nascente literatura no sólido tronco da arte greco-romana antiga: a calorosa e precoce recepção do público brasileiro ou estrangeiro a Marília de Dirceu, $^{25}$ por sinal, testemunha o quanto Gonzaga foi bem sucedido com essa iniciativa poética.

Résumé: On se propose, dans ce travail, de montrer quelques traits de la lyre première de Marilia de Dirceu, de l' "arcadien" portugais Tomás Antônio Gonzaga, dont l'existence nous renvoie, en général, à la tradition de la poésie pastoralle et, spécifiquement, à la deuxième Bucolique de Virgile. Ce sont d'éléments d'ordre thématique, structurelle, rhétorique et générique, auxquels on pourrait attribuer l'essai de dialogue de l'auteur du 18ème. siècle avec le passé de la littérature classique. De cette façon là, par le détachement de ce que Gonzaga doit à ces prédécesseurs, se fait voir aussi sa contribution personnelle au bucolisme.

25 Cf. prefácio de Ivan Junqueira à edição de Marilia de Dirceu preparada por Sergio Pachá (GONZAGA, 2001, p. XIII): A propósito, seria curioso aqui sublinhar que somente depois de 1860, quando a Marilia de Dirceul já havia alcançado trinta e duas ediçōes - incluindo-se entre elas a do primeiro livro de poesia brasileira a ser traduzido para uma língua estrangeira, o francês (Paris, 1824), edição da qual uma lira foi vertida para o russo por Puchkin é que Gonzaga foi suplantado, no favor do público, pelos poetas românticos, o que the confirmaria, ainda uma vez, essa índole pré-romântica. 


\section{REFERENCIAS}

ARISTÓTELES. HORÁCIO. LONGINO. A poética clássica. Trad. de Jaime Bruna. São Paulo: Cultrix, 1981.

ARISTÓTELES. Retórica. Introd., trad. y notas de Arturo Ramírez Trejo. México: Universidad Autónoma de México, 2002.

CANDIDO, Antonio. Formação da literatura brasileira. Belo Horizonte/ Rio de Janeiro: Itatiaia, 1993. Vol. I. . Uma aldeia falsa. In:

caderno de análise literária. São Paulo: Ática, 2002.

Na sala de aula:

FARIA, Alberto. Marília de Dirceu: seleção das liras autênticas. Rio de Janeiro: Anuário do Brasil, 1922.

FEDELI, Paolo. Bucolica, lirica, elegia. In: Montanari, Franco (org.). La poesia latina: forme, autori, problemi. Roma: NIS, 1991.

GONZAGA, Tomás Antônio. Marília de Dirceu. Texto estabelecido e anotado por Sergio Pachá. Rio de Janeiro: Academia Brasileira de Letras, 2001.

Rhetorica ad Herennium. Texterevu et trad. parHenri Bornecque. Paris: Garnier, s.d.

VIRGILE. Bucoliques. Texte ét. et trad. par Eugène de SaintDenis, intr. et notes par Jean-Pierre Néraudau. Paris: Les Belles Lettres, 2002. 